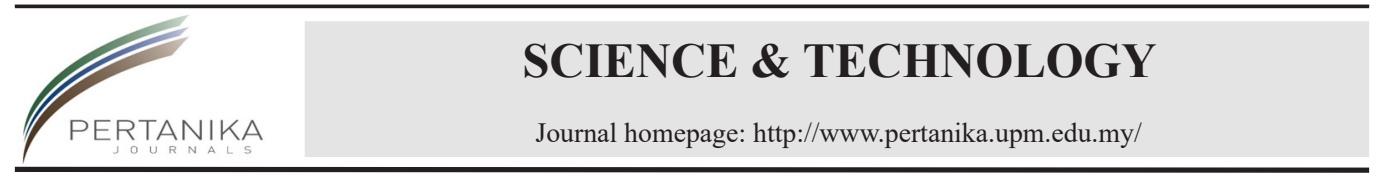

\title{
Development of Attendance and Temperature Monitoring System using IoT with Wireless Power Transfer Application
}

\author{
Noramalina Abdullah* and Sarah Madihah Mohd Shazali \\ School of Electric and Electronic Engineering, Universiti Sains Malaysia, Engineering Campus, 14300 USM, \\ Penang, Malaysia
}

\begin{abstract}
Enclosed areas pose a greater risk of transmitting infectious and bacterial diseases. The proposed system helps prevent disease by tracking students' daily body temperature before entering the school premises. Each student will be provided with a unique QR code containing the student information, such as their name and class. The QR code needs to be scanned first by the camera-equipped smartphone before reading the body temperature. The thermometer will record the student's body temperature and send the information to the smartphone via Bluetooth. The student's profile will be updated with the recorded daily temperature. An Android application will be developed to scan the QR code and display the students' profiles and information. In order to design a battery-less system, the system will be integrated with a wireless power transfer circuit. Based on the simulation results, the wireless power transfer circuit can be used as a wireless charger for the smartphone used in the system or for charging the thermometer' of the thermometer.
\end{abstract}

Keywords: Android application, Arduino, infrared thermometer, QR code, temperature monitoring, wireless power transfer

ARTICLE INFO

Article history:

Received: 17 August 2021

Accepted: 27 September 2021

Published: 10 January 2022

DOI: https://doi.org/10.47836/pjst.30.1.38

E-mail addresses:

eenora@usm.my (Noramalina Abdullah)

sarah.madihah@yahoo.com (Sarah Madihah Mohd Shazali)

*Corresponding author

\section{INTRODUCTION}

Viral and bacterial diseases, such as flu and cold, are very common diseases that researchers have been trying to develop a cure for, yet all the medicine available is to alleviate the symptoms instead of curing them (Alkhayat et al., 2015). The best approach for this problem is to avoid contracting the virus carrier to avoid spreading the disease among the community (Lee et al., 2012). 
Fever is one of the initial and typical symptoms indicating the presence of viruses in individuals, including SARS and COVID-19 (Addi et al., 2020). Omron, a Japanese electronics company, has mentioned on their website that the most accurate standards are taken from rectal measurement, which is $37.0^{\circ} \mathrm{C}$ to $37.5^{\circ} \mathrm{C}$. In contrast, oral measurement gives a slightly lower reading of $36.8^{\circ} \pm 0.4^{\circ} \mathrm{C}$. Furthermore, measurements were taken on the skin, such as axillary (armpit), tympanic (ear), and forehead, gives the lowest reading out of these types, which is $36.5^{\circ} \mathrm{C}$ (OmronHealthcare, 2020). Regarding the current pandemic, enforcement is required to record the attendees and their body temperature to detect early signs of fever, as fever is known as one of the symptoms that affect $89 \%$ of patients (Guan et al., 2020). A clinical analysis has found that conventional thermometry is better than self-reported fever when seasonal influenza patients are identified (Haghmohammadi et al., 2018).

Several papers propose a temperature monitoring system in detecting body temperature. Alkhayat et al. (2015) and Huang et al. (2016) suggested a fever detection system that uses multiple infrared cameras, which allowed the room temperature to be controlled and identify students that have a temperature higher than $37^{\circ} \mathrm{C}$ (Alkhayat et al., 2015; Huang et al., 2016). Apart from that, Somboonkaew et al. (2017) and Haghmohammadi et al. (2018) proposed the usage of thermal imaging from IR cameras. Their system does general screenings on random passers-by and does not collect any details of the person. Zhang (2018) developed a design of a non-contact infrared thermometer to compensate for the drawbacks of the traditional mercury thermometer to measure a single student at a time. MLX90614 infrared temperature sensor was used to collect the body temperature of the individual. Buzzer alarm was also included in his design to alert the user when the body temperature exceeds the set value, which is $37^{\circ} \mathrm{C}$. Ebeid et al. (2020) also designed a non-contact forehead thermometer with the purpose of early detection of Coronavirus with the accuracy of $\pm 0.3^{\circ} \mathrm{C}$.

This project includes the attendance tracking features with the temperature monitoring system, as the student needs to register themselves before taking their body temperature. There are several taking-attendance apart from the traditional attendance taking method in a class, such as fingerprints scanners, facial recognition, Radio-Frequency Identification (RFID), Bluetooth, and QR code (Monday et al., 2018). Other approaches that used the low-cost setup are Bluetooth, and QR codes did not require the usage of any other additional device apart from a personal-owned smartphone (Raj et al., 2019). As for Bluetooth, the main Bluetooth device detect all the MAC address, which is within its range, and automatically logs their attendance (Gohel, 2018). However, Bluetooth connection struggles in pinpointing the exact attendees, as sometimes, MAC addresses from passers-by can also be detected and included in the attendance data. 
Wireless power transfer (WPT) and data communication are important research problems with various applications. However, these two problems are usually studied separately. WPT is useful to electrical power devices where interconnecting wires are inconvenient, hazardous, or impossible. It consists of three mains: the transmitter circuit, receiver circuit, and coils. The transmitter's oscillator circuit transforms the input power into an electromagnetic field, transmitted by an antenna transmitter or coupling system. Similar coupling mechanisms on the recipient side are used to change the received electromagnetic field into an electric current, which the receiver devices may operate (Navin et al., 2017). He also reported that the frequency has a huge effect on the output power rate. A magnetic field will be generated from the WPT of the coils and metal. This project focuses on the magnetic resonant inductive coupling technique for applying a wireless charger system due to the high output power and the range of its distance. As the coil shape also affects the power transfer rate, the circular shape of the transmitter coil and receiver coil was chosen. According to research done by Shah and Abuzneid (2019), spiral coils was found to be more suitable compared to circular coils, as it has a higher Q-factor and consumes less space. With the recent technology and demand for a portable device, we are working on integrating the data communication aspect with WPT for a better consequence.

\section{METHODOLOGY}

\section{Implementation of Infrared Thermometer with $Q R$ code}

The proposed system uses a non-contact infrared thermometer and will include a QR code. The flowchart of the system design is shown in Figure 1.

The admin will generate a unique QR code during the student registration. The tag with the QR code, which acts similarly to a matric card and contains the links to the students' profiles, will then be provided to each student. As the student arrives at school, they will be required to scan their tag at the scanner in the smartphone. The phone will display the students' profiles, such as their names and classes. The time and attendance will be recorded as the students scan their tags. In addition, an infrared thermometer will be used to monitor the students' body temperature. There are two situations that the alarm will go off:

- The temperature is lower than $35.5^{\circ} \mathrm{C}$. It will prompt the student to retake the reading until the temperature is within the acceptable range $\left(35.5^{\circ} \mathrm{C}-37.5^{\circ} \mathrm{C}\right)$.

- The temperature is higher than $37.5^{\circ} \mathrm{C}$. It will alert the teacher that the student has a fever and further action needs to be taken by the school.

The whole procedure has practically accomplished and successes. 


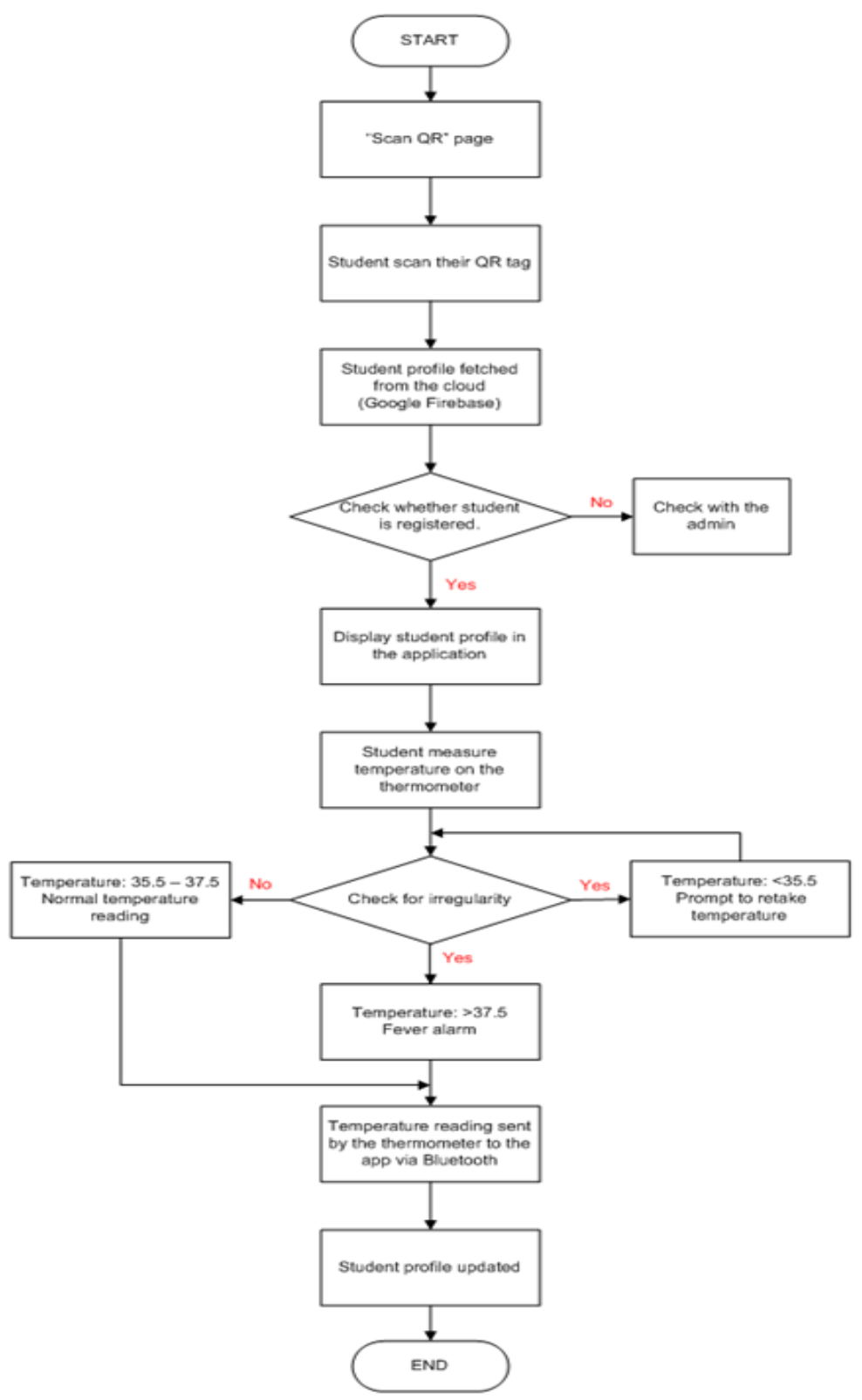

Figure 1. Flowchart of temperature measurement process

\section{Implementation of Arduino Microcontroller}

Figure 2 shows the circuit of the contactless IF thermometer. The thermometer consists of an MLX90614 infrared temperature sensor connected to an Arduino microcontroller. The whole procedure has practically accomplished and successes. 


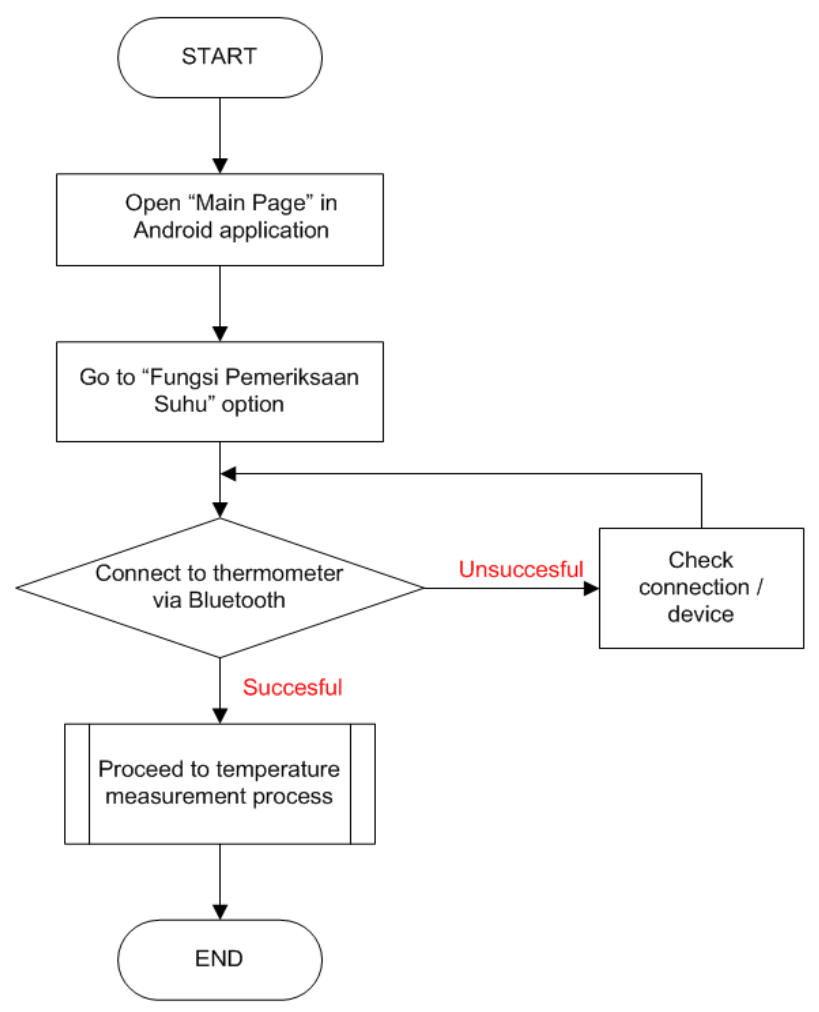

Figure 2. Flowchart of the initial process before temperature measurement process

For normal temperature, the data will automatically be updated to the student's profile and the school's database. When the scanner detects an abnormal temperature, the alarm will go off. In addition, the APDS9960 proximity sensor will be installed on the thermometer. The APDS9960 proximity sensor helps minimise contact, as it can detect the presence of nearby objects without direct physical contact and thus automatically activate the thermometer. It will automatically activate the thermometer once it detects the presence of nearby objects.

An LCD was used to display the body temperature reading. If the thermometer detects an abnormally low-temperature reading, which is less than $35.5^{\circ} \mathrm{C}$, the default message of "NOT DETECTED" will be displayed, thus prompting the user to retake their temperature. This message was displayed when the user stood too far for the thermometer to get an accurate body temperature reading. When the thermometer detects a temperature higher than $37.5^{\circ} \mathrm{C}$, the LCD will produce a warning message, and the buzzer will produce a loud beep to alert the teacher. In order to test the accuracy of the system thermometer, the body temperature reading taken by the system thermometer was compared with the temperature 
taken by the $\mathrm{K} 3$ infrared thermometer, which is currently available in the market and widely used in public premises, such as hospitals, restaurants, and shops. In addition, the time to measure the student's body temperature was taken at various times every day to get various ambient temperature readings throughout the day.

\section{Implementation of Bluetooth}

A Bluetooth module (HC-05 Arduino) will also be connected to the circuit to send the data from the thermometer to a smartphone. For scanning the QR code, an Android application was developed in AndroidStudio. The whole procedure has practically accomplished and successes.

The application can be connected to the Bluetooth module in the thermometer circuit, thus allowing the temperature reading to be sent to the smartphone and updated in the student's profile. The process of connecting the thermometer to the application is shown in Figure 3. The application also allows the teacher to install and view the scanned history of any recorded day. The system used Google Firebase as its database. The Android application will only be distributed to teachers and admin, thus allowing teachers to access the student profile just from their mobile phone to check and view the student's details and attendance. However, the registration of new students and the profile editing process can only be done by the admin, as shown in Figure 4.

\section{Application of WPT}

With the advantages of WPT, it will be used as a mobile phone charger. The whole procedure has been completely done by using simulation.

Two circuits are involved: the transmitter (Figure 5) and receiver (Figure 6). These circuits are simulated in the Proteus software. The transmitter circuit consists of an oscillator circuit and transmitter coil used to transmit the voltage wirelessly. For the oscillator circuit, a Royer oscillator is chosen, as it has many advantages, such as the simplicity of the design and lesser components required for the circuit. The operating frequency formula for the resonance circuit (Equation 1),

$$
F=\frac{1}{2 \pi \sqrt{(L C)}}
$$

The oscillator circuit consists of two n-channel MOSFET, two 1N4148 diodes, two $4.7 \mathrm{k} \Omega$ resistors, two $470 \Omega$ resistors and a $330 \mu \mathrm{H}$ inductor. As for the transmitter coil, it is connected to the oscillator circuit with a $1 \mu \mathrm{F}$ capacitor. The receiver circuit, which receives the wireless voltage from the transmitter circuit, consists of a receiver coil, rectifier circuit and a voltage regulator. The receiver coil, consisting of $7 \mu \mathrm{H}$ inductive coils and a $1 \mu \mathrm{F}$ capacitor, is connected to the receiver circuit. By using Equation 1, the resonance frequency for the circuit was calculated. 


$$
\begin{gathered}
F=\frac{1}{2 \pi \sqrt{ }\left(\left(7 \times 10^{-6}\right)\left(1 \times 10^{-6}\right)\right)} \\
F=60.15 \mathrm{kHz}
\end{gathered}
$$

The circuit includes a bridge rectifier which will rectify the input AC voltage to DC voltage. Four individual rectifying diodes are used and connected in a full-wave bridge arrangement. A smoothing capacitor will also be added across the output of the bridge rectifier to convert the full-wave voltage ripple from the rectifier to a smooth DC output voltage. The main advantage of using a full-wave bridge rectifier instead of a half-wave bridge rectifier is that the former produces a smaller AC ripple for the given load, making it more stable. The receiver circuit consists of four diodes, a $1 \mu \mathrm{F}$ capacitor, a 7805 -voltage regulator and a $1 \mu \mathrm{F}$ capacitor smoothing capacitor. Seven thousand eight hundred five voltage regulators are used to produce a regulated $5 \mathrm{~V}$ output from the DC voltage obtained from the rectifier. In addition, the smoothing capacitor will act as a filter to smoothen the DC voltage from the rectifier.

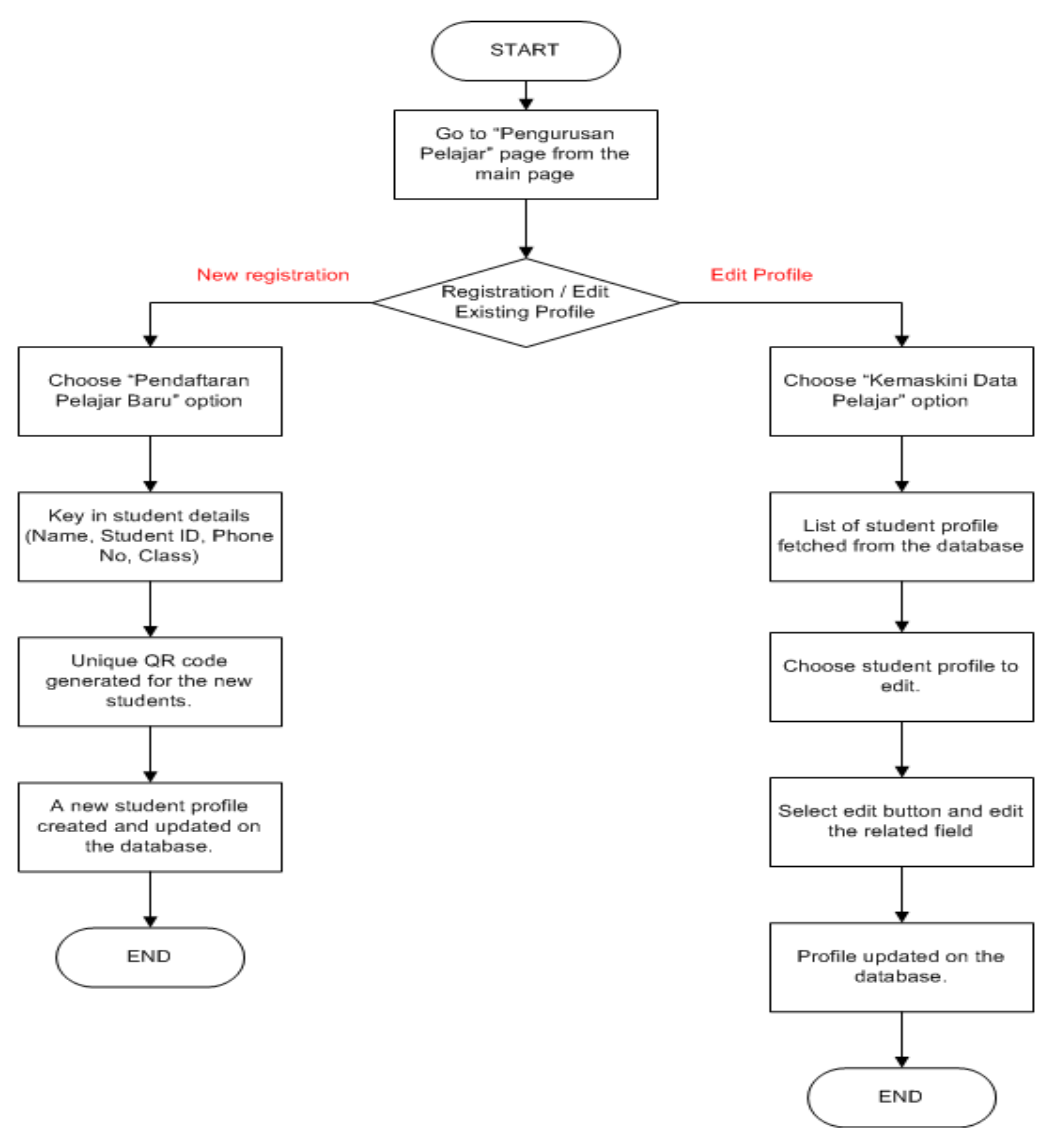

Figure 3. Flowchart for the student management process (can only be accessed by admin) 


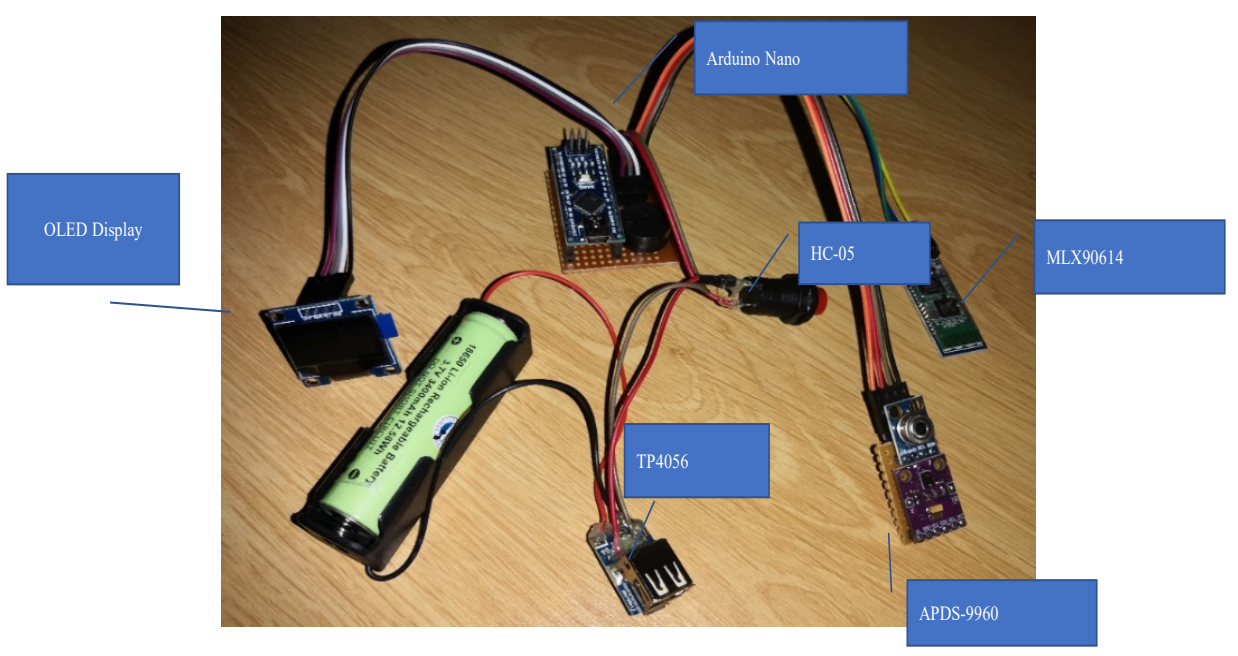

Figure 4. Circuit of the non-contact infrared thermometer

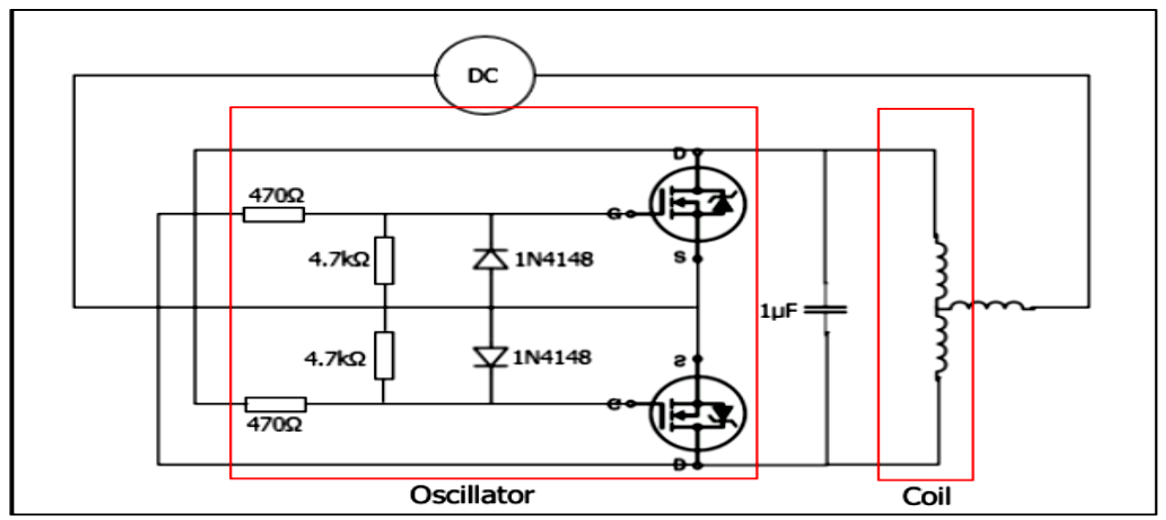

Figure 5. Transmitter circuit

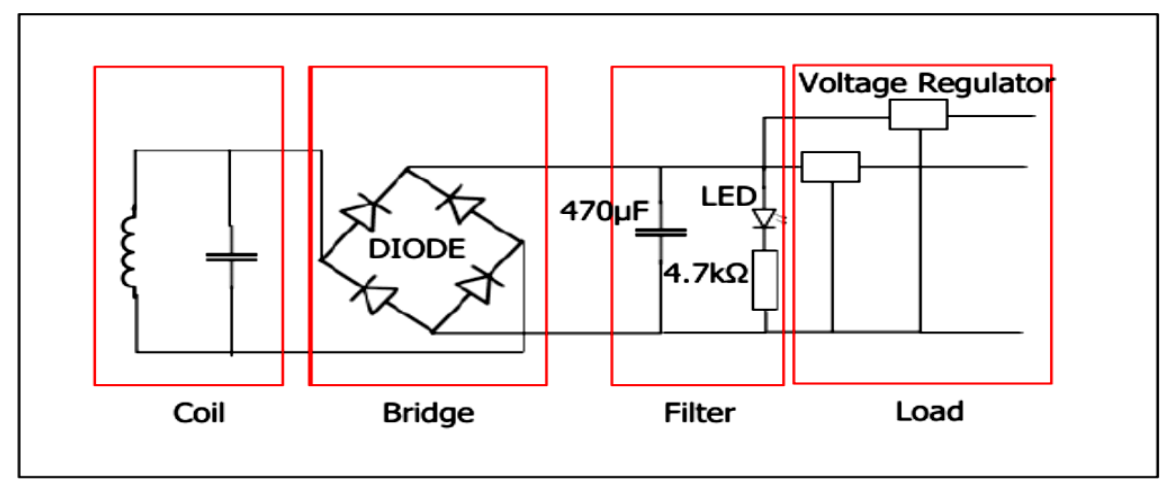

Figure 6. Receiver circuit 


\section{RESULTS AND DISCUSSION}

\section{Results for Temperature Detection and Analysis}

When the thermometer takes the body, the temperature detects a reading lower than $35.5^{\circ} \mathrm{C}$, the temperature taken will be considered an error, and the temperature will not be recorded into the system. The display will show the "NOT DETECTED" message, as shown in Figure 7 until the thermometer can take a reasonable temperature reading. In contrast, for temperatures above $35.5^{\circ} \mathrm{C}$, the measured body temperature will be displayed on the OLED, as shown in Figure 8, and recorded in the student's profile. The alarm will be triggered for this system, and loud noise will be produced from the buzzer when the body temperature taken by the system thermometer detects a temperature higher than $37.5^{\circ} \mathrm{C}$, as shown in Figure 9. It indicates that the student has a fever, as stated in the Ministry of Health guidelines of normal body temperature. The body temperature reading was taken from 4 students. Their average temperature for the day was taken to see the relation between the ambient temperature and the average body temperature. The lowest ambient temperature was at $28.58^{\circ} \mathrm{C}$ on Day 9 . At the same time, the highest ambient temperature reading was at $34.23^{\circ} \mathrm{C}$ on Day 4.

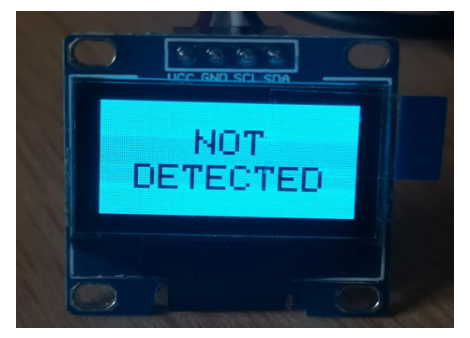

Figure 7. Default message for when error temperature is detected

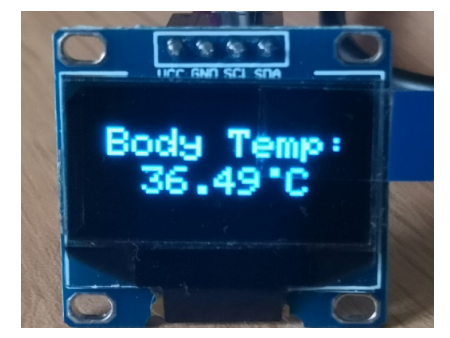

Figure 8. Normal body temperature reading

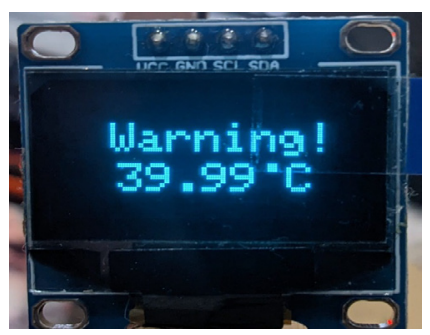

Figure 9. High body temperature reading

The readings in Figure 10 and Figure 11 show the temperature reading comparison taken by the system's thermometer (ST) and K3 infrared thermometer (K3). Figure 10 shows the obtained temperature reading when the ambient temperature is highest, while Figure 11 shows the temperature readings when the ambient temperature is lowest. Based on Figure 10 and Figure 11, the average difference in body temperature taken by the system thermometer and $\mathrm{K} 3$ thermometer is in the range of \pm 0.01 . Thus, it can be said that the system thermometer is considered reliable and is on par in terms of accuracy, with other available thermometers on the market. The result is further proven statistically using SPSS. 


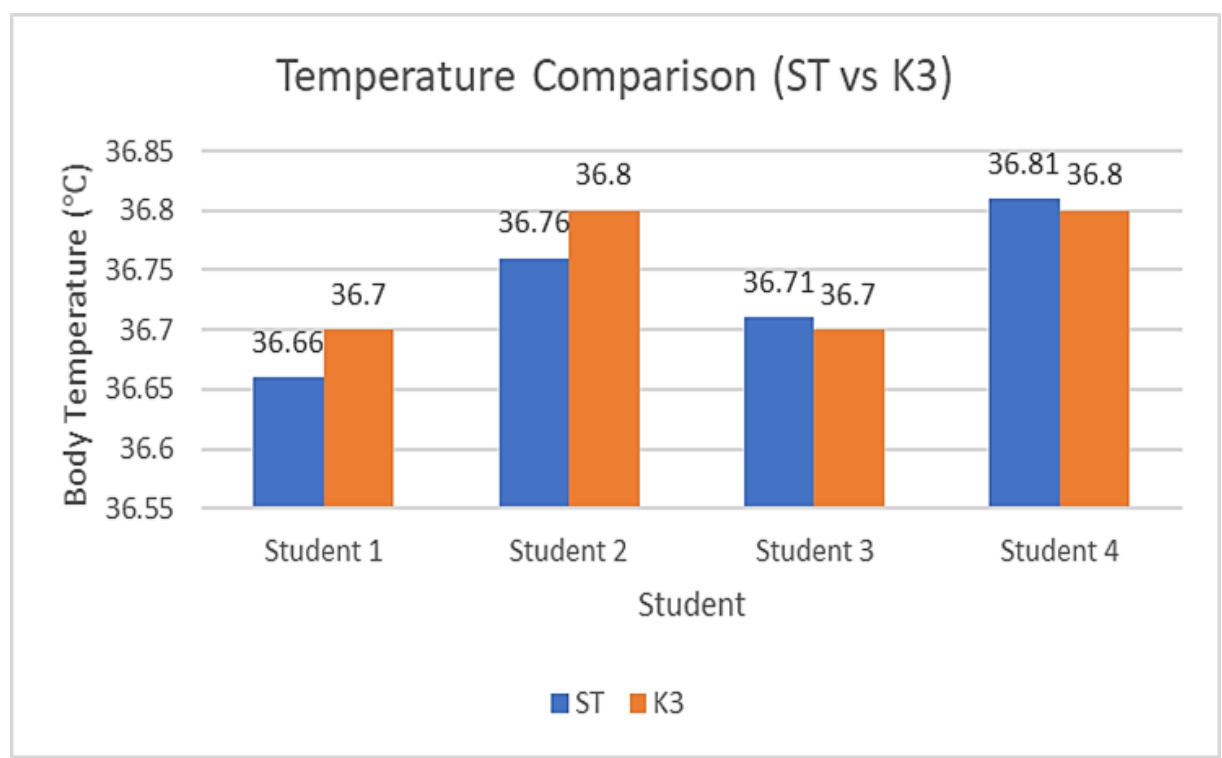

Figure 10. Temperature comparison between system thermometer (ST) and K3 infrared thermometer (K3) when ambient temperature is at the highest $\left(34.23^{\circ} \mathrm{C}\right)$

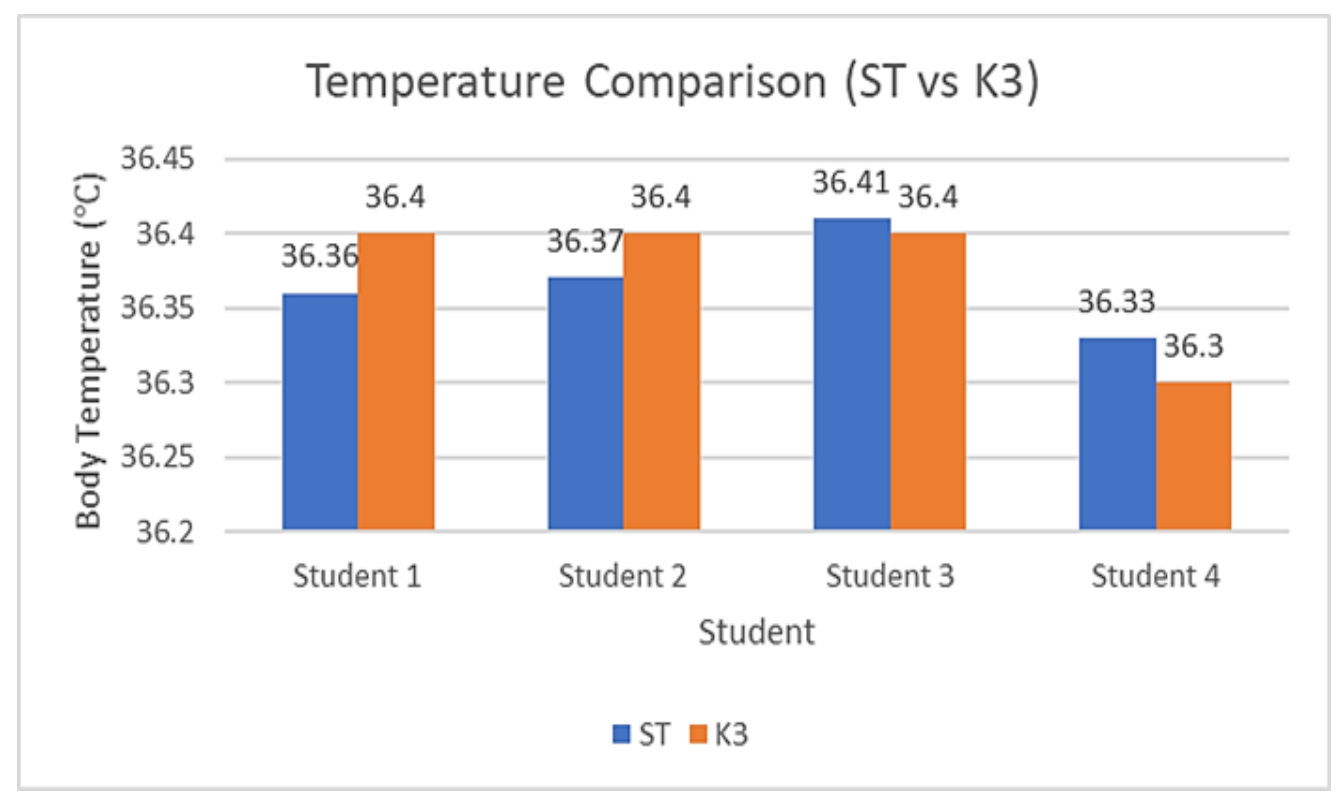

Figure 11. Temperature comparison between system thermometer (ST) and K3 infrared thermometer (K3) when ambient temperature is at the lowest $\left(28.58^{\circ} \mathrm{C}\right)$ 
This result found that the mean value of the system thermometer, ST $\left(36.53 \pm 0.03^{\circ} \mathrm{C}\right)$, is relatively similar to the mean value of the $\mathrm{K} 3$ thermometer $\left(36.55 \pm 0.03^{\circ} \mathrm{C}\right)$ with a very small mean difference between these two methods $\left(0.03^{\circ} \mathrm{C}\right)$. Statistically, there is no significant difference observed between the mean values of ST and K3 ( $\mathrm{p}=0.548)$. Therefore, it is noted that the reading of both ST and $\mathrm{K} 3$ was relatively equal and could be implemented. When the ambient temperature is high at $34.23^{\circ} \mathrm{C}$, the average body temperature is around $36.74^{\circ} \mathrm{C}$. The relation between these two parameters can be seen further seen in Figure 12, where the ambient temperature has shown significant positive correlations with $\mathrm{ST}(\mathrm{r}=0.728, \mathrm{p}<0.01)$ as well as $\mathrm{K} 3$ thermometer $(\mathrm{r}=0.778, \mathrm{p}<0.01)$. Therefore, it can be deduced that the increase or decrease of ST and K3 thermometers are significantly associated with the changes in the ambient temperature when the reading is taken, which should be within ten days. Based on the overall reading, the recorded body temperature taken is between $36.2^{\circ} \mathrm{C}$ to $36.9^{\circ} \mathrm{C}$. Statistically, using SPSS proves that the ambient temperature strongly affects the temperature reading taken by $\mathrm{ST}$ and $\mathrm{K} 3$.

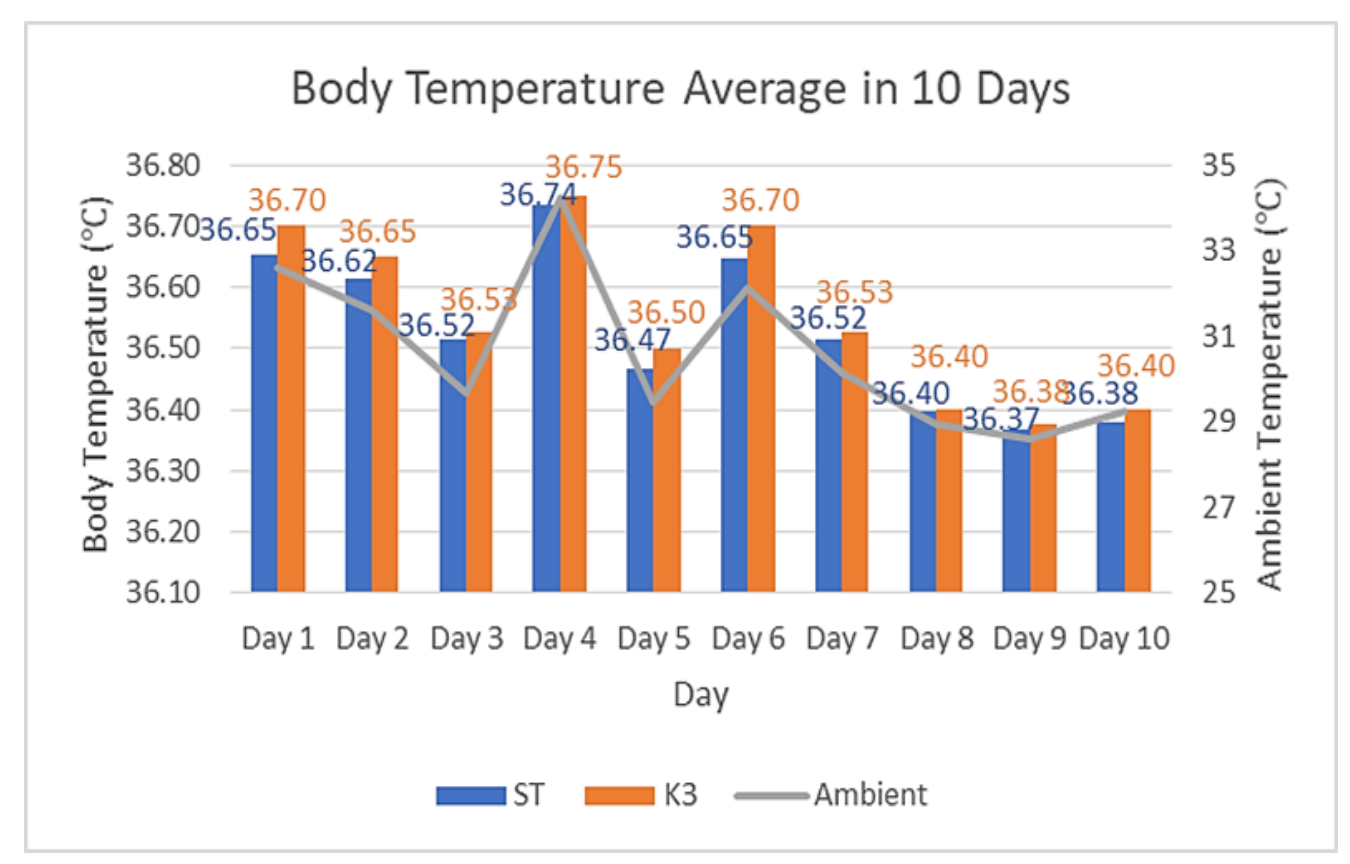

Figure 12. Average body temperature reading in the span of 10 days 


\section{Results with Android Application}

There are three main features included in the Android application, which are: (i) Student Management, (ii) Admission History, and (iii) Temperature Checking Function. The "Student Management" feature allows the teacher to register new students or edit the existing students' information. Once a new student is registered, a unique QR code will be generated automatically. The code can be printed and attached to the tag for the student to use while scanning. Student's history can be viewed as well, which includes the date and time when the student's scan their tag and the temperature recorded at that time, as shown in Figure 13 (a), (b) and (c), respectively. Finally, the "Admission History" feature allows the teacher to view the scan history for the day or the overall history. For example, in Figure 13 (c), the list shows the student's name, class, the temperature recorded by the thermometer, and the date and time when the tag is scanned. In addition, it allows the teacher to check for any lack of punctuality or absentees.
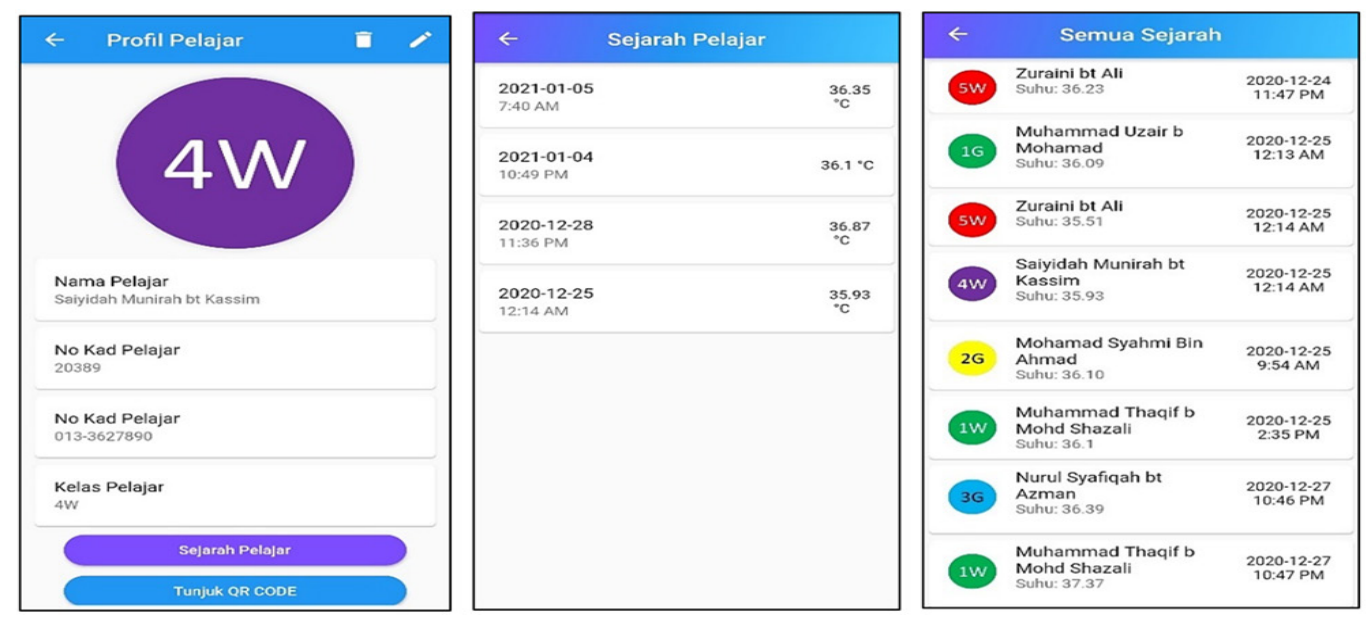

Figure 13. IoT information platform (a)Student's profile (b) Student history (c) Overall history

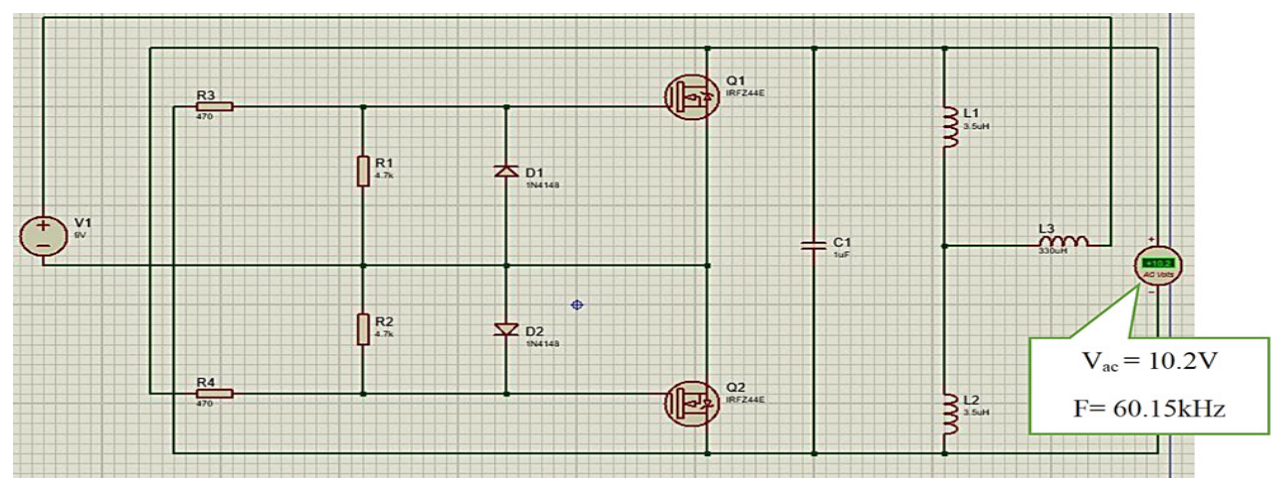

Figure 14. Transmitter circuit with inductive coil of $7 \mu \mathrm{H}$ 


\section{Results with Bluetooth-QR Code Verification}

As for the "Temperature Checking Function" feature, it is used for temperature checking. By selecting this option, a Bluetooth configuration page will pop up, which allows the smartphone to connect to the thermometer via Bluetooth. Once the connection is established, the student will be required to scan their forehead, and after the temperature is recorded, a page with a QR scanner will pop up, allowing the student to scan their tag. Next, the detected temperature will then be updated to the profile that belongs to the scanned tag.

\section{Results with WPT Simulation}

The transmitter circuit in Figure 14 will transmit the power wirelessly to the receiver circuit. The testing inductance value used in the simulation is $7 \mu \mathrm{H}$. By referring to Equation 1, the inductance value is high while the operating frequency is low. As for the receiver circuit illustrated in Figure 15, the input for the voltage source is obtained from the output at the transmitter circuit. A minimum output of $5 \mathrm{~V}$ is needed to comply with the requirement for the WPT application. The simulation results show that the circuit can produce a voltage output of more than $5 \mathrm{~V}$. The output voltage can be tuned based on the value of inductance used in the circuit. The number of turns for the coils can be varied to adjust the inductance value. The results show that the system can be powered using WPT instead of a rechargeable battery.

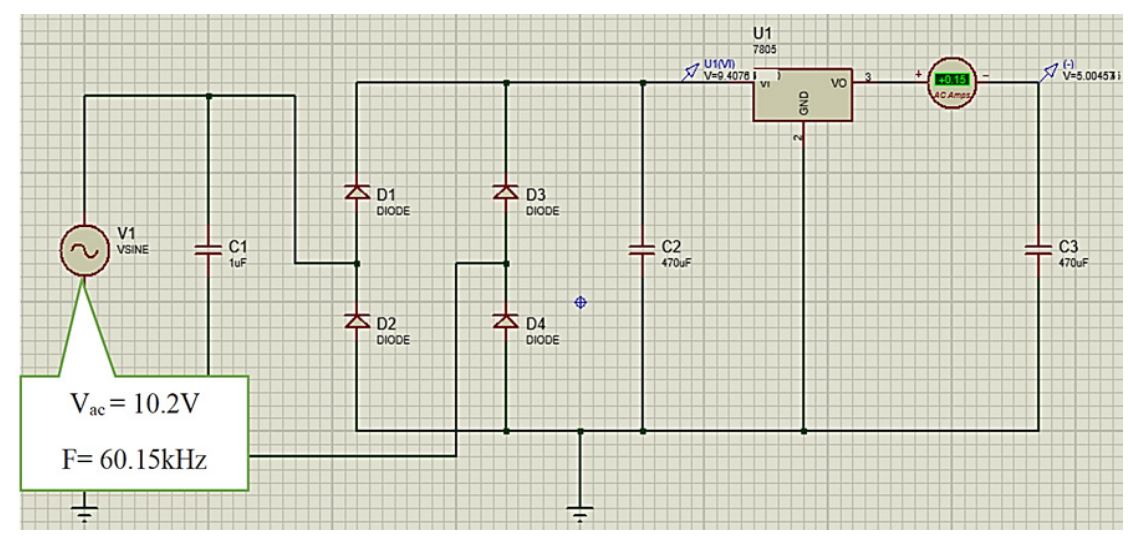

Figure 15. Receiver circuit with inductive coil of $7 \mu \mathrm{H}$

\section{CONCLUSION}

The proposed system included the attendance-taking method using the QR Code to integrate an Android application and simulation for WPT purposes. We have successfully developed the IoT platform with useful information. It is the most contribution we have achieved 
compared with other research works. Furthermore, we have successfully investigated the potential integration with wireless power transfer. The wireless power circuit will be practically integrated into the system to make the system more portable and to charge the thermometer's battery. The finding will be further implemented to other premises for an efficient attendance record and monitoring. In the future, a web-based platform can also be included in the system, apart from the current Android application installed in the teacher's phone, for an easier monitoring process.

\section{ACKNOWLEDGEMENTS}

The authors would like to thank the Department of Research and Innovation Universiti Sains Malaysia for giving the opportunity and support throughout the completeness of this work.

\section{REFERENCES}

Addi, R. A., Benksim, A., Amine, M., \& Cherkaoui, M. (2020). Asymptomatic COVID-19 infection management: The key to stop COVID-19. Journal of Clinical and Experimental Investigations, 11(3), 1-2. https://doi.org/10.5799/jcei/7866

Alkhayat, A. H., Bagheri, N., Ayub, M. N., \& Noor, N. F. M. (2015). Fever detection \& classroom temperature adjustment: Using infrared cameras. In 2015 IEEE International Conference on Consumer ElectronicsTaiwan (pp. 240-241). IEEE Publishing. https://doi.org/10.1109/ICCE-TW.2015.7216876

Ebeid, A. G., Selem, E., \& El-Kader, S. M. A. (2020). Early detection of COVID-19 using a non-contact forehead thermometer. In International Conference on Advanced Intelligent Systems and Informatics (pp. 314-323). Springer. https://doi.org/10.1007/978-3-030-58669-0_29

Gohel, S. (2018). Bluetooth attendance system with android application for ERP. In 2018 International Conference on Computing, Power and Communication Technologies (GUCON) (pp. 481-484). IEEE Publishing. https://doi.org/10.1109/GUCON.2018.8674898

Guan, W., Ni, Z., Hu, Y., Liang, W., Ou, C., He, J., Liu, L., Shan, H., Lei, C., Hui, D. S. C., Du, B., Li, L., Zeng, G., Yuen, K. Y., Chen, R., Tang, C., Wang, T., Chen, P., Xiang, J., Zhong, N. (2020). Clinical characteristics of Coronavirus disease 2019 in China. New England Journal of Medicine, 382(18), 1708-1720. https:// doi.org/10.1056/NEJMoa2002032

Haghmohammadi, H. F., Necsulescu, D. S., \& Vahidi, M. (2018). Remote measurement of body temperature for an indoor moving crowd. In 2018 IEEE International Conference on Automation, Quality and Testing, Robotics (AQTR) (pp. 1-6). IEEE Publishing. https://doi.org/10.1109/AQTR.2018.8402698

Huang, P. W., Chang, T. H., Lee, M. J., Lin, T. M., Chung, M. L., \& Wu, B. F. (2016). An embedded non-contact body temperature measurement system with automatic face tracking and neural network regression. In 2016 International Automatic Control Conference (CACS) (pp. 161-166). IEEE Publishing. https://doi. org/10.1109/CACS.2016.7973902 
Lee, B., Yoon, J., Kim, S., \& Hwang, B. Y. (2012). Detecting social signals of flu symptoms. In 8th International Conference on Collaborative Computing: Networking, Applications and Worksharing (CollaborateCom) (pp. 544-545). IEEE Publishing. http://dx.doi.org/10.4108/icst.collaboratecom.2012.250355

Monday, H. N., Dike, I. D., Li, J. P., Agomuo, D., Nneji, G. U., \& Ogungbile, A. (2018). Enhanced attendance management system: A biometrics system of identification based on fingerprint. In 2018 IEEE 9th Annual Information Technology, Electronics and Mobile Communication Conference (IEMCON) (pp. 500-505). IEEE Publishing. https://doi.org/10.1109/iemcon.2018.8614776

Navin, K., Shanthini, A., \& Krishnan, M. B. M. (2017). A mobile based smart attendance system framework for tracking field personals using a novel QR code-based technique. In 2017 International Conference on Smart Technologies for Smart Nation (SmartTechCon) (pp. 1540-1543). IEEE Publishing. https://doi. org/10.1109/smarttechcon.2017.8358623

OmronHealthcare. (2020). Does the temperature reading depend on the body part where the reading is taken? Omron Healthcare. Retrieved November 5, 2020, from https://www.omronhealthcare-ap.com/my/faqs/ temperature-measurement/406

Raj, R., Das, A., \& Gupta, S. C. (2019). Proposal of an efficient approach to attendance monitoring system using Bluetooth. In 2019 9th International Conference on Cloud Computing, Data Science \& Engineering (Confluence) (pp. 611-614). IEEE Publishing. https://doi.org/10.1109/confluence.2019.8776978

Shah, S. N., \& Abuzneid, A. (2019). IoT based smart attendance system (SAS) using RFID. In 2019 IEEE Long Island Systems, Applications and Technology Conference (LISAT) (pp. 1-6). IEEE Publishing. https://doi. org/10.1109/LISAT.2019.8817339

Somboonkaew, A., Prempree, P., Vuttivong, S., Wetcharungsri, J., Porntheeraphat, S., Chanhorm, S., \& Sumriddetchkajorn, S. (2017). Mobile-platform for automatic fever screening system based on infrared forehead temperature. In 2017 Opto-Electronics and Communications Conference (OECC) and Photonics Global Conference (PGC) (pp. 1-4). IEEE Publishing. https://doi.org/10.1109/oecc.2017.8114910

Zhang, J. (2018). Development of a non-contact infrared thermometer. In 2017 International Conference Advanced Engineering and Technology Research (AETR 2017) (Vol. 153). Atlantis Press. https://doi. org/10.2991/aetr-17.2018.59 
